\title{
AN INVESTIGATION OF "NORMAL" ON THE SYNOPTOPHORE*
}

\author{
BY \\ M. M. LEWIS \\ (FORMERLY ORTHOPTIST AT THE CENTRAL VISION \\ TRAINING SCHOOL, R.A.F.)
}

FOR many years the synoptophore has been used as a means for measuring and treating ocular muscle imbalance. No work has apparently been done to show whether the results are repeatable, whether the range of normal is wide or narrow, or whether there is a high correlation between the synoptophore and other methods of measuring ocular muscle imbalance.

In this investigation 98 young adult males (aircrew) and 2 W.A.A.F., aged 18-30 years, were examined to determine :-

(a) The "normal" range of synoptophore measurements.

(b) The repeatability of the measurements.

(c) The results using two different methods of measurement.

(d) A comparison between the synoptophore simultaneous perception readings and the commonly used Maddox rod test for heterophoria.

None of these young men and women complained of any symptoms referable to their eyes.

\section{Apparatus}

1. Synoptophore with scale in prism dioptres. The calibration of the instrument remained constant throughout the experiment.

Facilities to check the zero position on the scale were not available, but there was no reason to doubt that the zero was reasonably. accurate.

2. Red Maddox rod and separate prisms, with spotlight at 20 feet.

3. Millimetre rule.

4. Snellen test type at 20 feet.

\section{Methods}

Each subject had the following measurements done:(a) Visual Acuity. No refractions were done, and no corrections were worn for synoptophore measurements.

(b) Maddox rod. The Maddox rod was placed before the right eye, and prisms were used to measure the heterophoria. This procedure was then carried out with the rod before the left eye. In a few cases a slight difference between the two readings was found. The

\footnotetext{
* Received for publication, October, 1946.
} 
difference was rarely as much as 1 prism dioptre. Since synoptophore measurements were taken with the right eye fixing, in the analysis of results that follows Maddox rod readings with the rod before the left eye (right eye fixing spot light) have been used.

(c) Interpupillary distance. This was measured from centre of the right pupil to the centre of the left pupil.

(d) Synoptophore. This was adjusted for the interpupillary distance of each subject, and readings taken as follows:-

1. Simultaneous perception. Slides 1 and 2 (Fig. 1) were used, slide 1 before the right eye and slide 2 before the left.

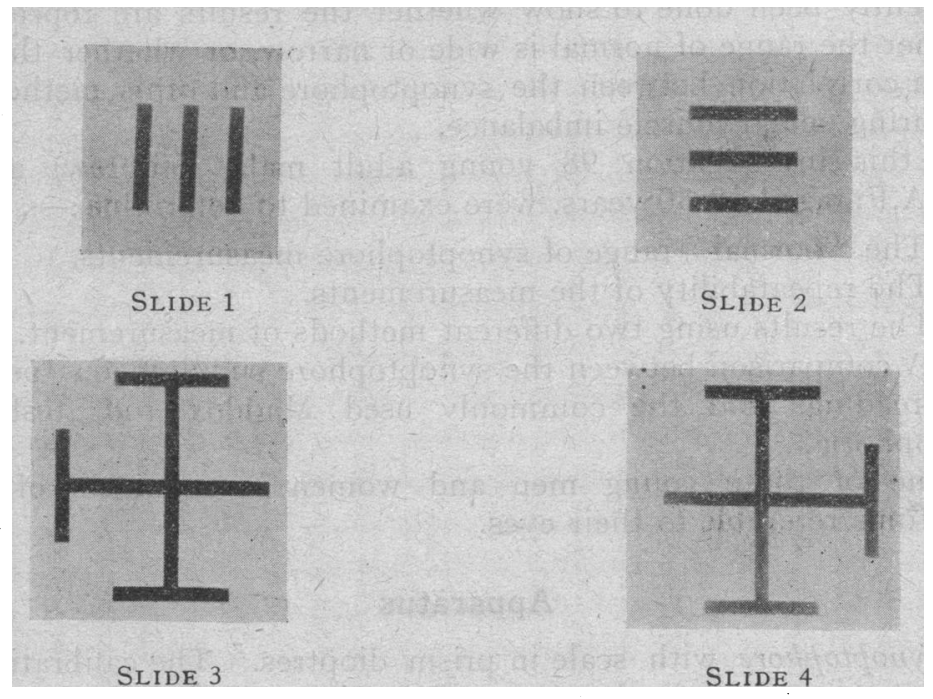

FIG. 1.

Method $A$. The right synoptophore tube was set at 0 , and the subject fixed the centre of slide 1 with his right eye. The left synoptophore tube with slide 2 was set at approximately -15 prism dioptres. The subject was asked to move the left synoptophore tube until the two sets of lines appeared superimposed. The synoptophore scale reading was recorded. This measurement was made four times.

Method $B$. The above was repeated, but with the left synoptophore tube set at approximately +15 prism dioptres.

2. Fusion. Slide 3 for the right eye and slide 4 for the left eye were used (Fig. I).

Method A. This was exactly as for method A above. The measurement was made twice.

Method $B$. The above was repeated, but with the left synoptophore tube set at approximately +15 prism dioptres.

3. Abduction. Slides 3 and 4 were again used. Fusion was first 
obtained using method $\mathrm{A}$ above. The synoptophore tubes were then locked, and the subject instructed to look at the centre of the picture. Abduction was measured by slowly turning the abduction screw until the pictures no longer appeared fused. The reading was noted, and the measurement repeated.

4. Adduction. Fusion was once more obtained by method A, using slides 3 and 4 . The synoptophore tubes were locked, and the subject instructed to look at the centre of the picture. He was told that the picture would probably get blurred, and that if it did, he was not to try to see it clearly. He was also told that the picture would gradually appear to get smaller. Adduction was measured by slowly turning the adduction screw until the pictures no longer appeared fused. The reading was noted and the whole procedure repeated.

\section{Results}

I. Visual acuity. This varied between $6 / 5$ and 6/18. There was only one person with visual acuity as low as $6 / 18$.

II. Synoptophore. All readings are in prism dioptres.

(i) Simultaneous perception.

\begin{tabular}{crrrrr} 
Method A & & \multicolumn{1}{c}{1} & \multicolumn{1}{c}{3} & \multicolumn{1}{c}{3} \\
Mean $\ldots$ & $\ldots$ & $-2 \cdot 84$ & $-3 \cdot 08$ & $-3 \cdot 15$ & $-3 \cdot 16$ \\
Standard deviation & $2 \cdot 24$ & $2 \cdot 33$ & $2 \cdot 15$ & $2 \cdot 05$
\end{tabular}

The means of readings 1 and 4 show the greatest difference. The standard error of the difference between these two means is 0.304 . The difference between these means is not significant, being only the same as the standard error.

$\begin{array}{crrrrr}\text { Method } B & & 1 & 2 & 3 & 4 \\ \text { Mean } & \ldots & -1 \cdot 68 & -1 \cdot 48 & -1 \cdot 22 & -1 \cdot 31 \\ \text { Standard deviation } & 2 \cdot 28 & 2 \cdot 15 & 2 \cdot 29 & 2 \cdot 29\end{array}$

The means of readings 1 and 3 show the greatest difference. The standard error of the difference between these two means is 0.313 , which again is practically the same as the difference. No significant difference therefore occurs between the means.

Joint consideration of methods $\mathrm{A}$ and $\mathrm{B}$ gives the following series of standard errors :-

1 st reading of both methods (means $-2{ }^{*} 84$ and $-1^{\circ} 68$ ) S.E. $=0.320$ 2nd reading of both methods (means $-3^{\circ} 08$ and $-1^{\circ} 48$ ) S.E. $=0.317$ 3rd reading of both methods (means $-3^{\circ} 15$ and $-1^{\circ} 22$ ) S.E. $=0.314$ 4 th reading of both methods (means -3.16 and -1.31 ) S.E. $=0.307$

The differences between the means are all significant, as they vary from 3 to 6 times the respective standard errors.

The test-retest correlation of the first and second readings using method A is +0.926 . 
(ii) Fusion.

Method $A$

$$
\begin{array}{lrrr} 
& 1 & 3 \\
\text { Mean } \ldots & -3 \cdot 12 & -3 \cdot 04 \\
\text { Standard deviation } & 2 \cdot 04 & 2 \cdot 28
\end{array}
$$

Method B

$$
\begin{array}{lrrr}
\text { Mean } \ldots & -1.82 & -1.49 \\
\text { Standard deviation } & 2.23 & 2.27
\end{array}
$$

The standard error of the difference between the means of the first and second readings of method $\mathrm{A}$ is 0.306 .

The standard error of the difference between the means of the first and second readings of method $B$ is 0.318 .

The differences between the means are not significant, as in both cases the differences are less than the respective standard errors.

The standard errors of the difference between the means of the fusion readings obtained by method $A$ and by method $B$, are as follows :-

1 st reading of both methods (means $-3^{\circ} 12$ and $-1^{\circ} 82$ ) S.E. $=0.302$ 2nd reading of both methods (means $-3^{\circ} 04$ and $-1^{\circ} 49$ ) S.E. $=0.312$

The differences between these means are significant, as they vary from four to five times the respective standard errors.

The standard errors of the difference between the means of the simultaneous perception readings and the fusion readings, are as follows :-

1st reading of S.P. method $A$ and of fusion method $A$ (means $-2 \cdot 84$ and $-3 \cdot 12$ ) S.E $=0.304$

2nd reading of S.P. method $A$ and of fusion method $A$ (means -3.08 and -3.04 ) S.E. $=0.325$

7 st reading of S.P. method $B$ and of fusion method $B$

$$
\text { (means }-1.68 \text { and }-1.82 \text { ) S.E. }=0.319
$$

2nd reading of S.P. method $B$ and of fusion method $B$

$$
\text { (means }-1.48 \text { and }-1.49 \text { ) S.E. }=0.313
$$

The differences between these means are not significant, since each difference is less than the corresponding standard error.

(iii) Abduction

$1 \quad 2$

$\begin{array}{lrrr}\text { Mean } \ldots & \ldots & -7 \cdot 61 & -6.91 \\ \text { Standard deviation } & 2 \cdot 19 & 2.57\end{array}$

The standard error of the difference between the means is 0.34 . The difference between the means is therefore on the borderline of significance, as it is equal to twice the standard error.

$\begin{array}{ccrr}\text { (iv) Adduction } & & 1 & 2 \\ \text { Mean } \ldots & \ldots & +27.09 & +29 \cdot 83 \\ \text { Standard deviation } & 22.93 & 22.05\end{array}$

The standard error of the difference between the means is $3 \cdot 18$. The difference between the means is less than the standard error, and therefore is not significant. 
III. Maddox rod.

$$
\begin{array}{llr}
\text { Mean } & \ldots & +0.89 \\
\text { Standard deviation } & 1.18
\end{array}
$$

The correlation co-efficient of the first simultaneous perception readings (method $\mathrm{A}$ ) and the Maddox rod readings is +0.479 .

\section{Conclusions}

The following conclusions apply to those examined:-

\section{Synoptophore.}

(i) Simultaneous perception-(a) Analysis of the results shows that there is no significant difference between four readings taken in succession on the same person by the same method (A or B).

(b) There is a significant difference between readings taken by method $A$ and method $B$. The difference between the means obtained by method A and method B are shown below for four successive sets of readings :-

$\begin{array}{cccc}1 & 2 & 3 & 4 \\ 1.16 & 1 \cdot 60 & 1.93 & 1 \cdot 85\end{array}$

(c) The readings obtained by method $\mathrm{A}$ are more exophoric than those obtained by method B.

(d) The test-retest correlation of the first and second simultaneous perception readings (method $\mathrm{A}$ in each case) is very high, +0.926 .

(ii) Fusion-(a) There is no significant difference between two readings taken in succession on the same person by the same method (A or B).

(b) There is a significant difference between readings taken by method $\mathrm{A}$ and method 13 . The difference between the means obtained by method $A$ and method $B$ are shown below for two successive sets of readings :-

$$
\begin{array}{cc}
1 & 2 \\
1 \cdot 30 & 1 \cdot 55
\end{array}
$$

(iii) Simultaneous perception and fusion-Readings obtained by means of simultaneous perception slides do not differ significantly from those obtained by the use of fusion slides, provided the slides are used in the same manner (e.g. method A or method B).

(iv) Abduction and Adduction-No significant difference was found between two successive readings in the case of either abduction or adduction.

2. Maddox rod and synoptophore.

(i) Correlation co-efficient $=+0.479$.

There is some correlation between the Maddox rod and synoptophore readings. It would appear that the two devices do not measure identical qualities of heterophoria.

(ii) The results obtained by the synoptophore are more exophoric than those obtained by the Maddox rod. (See Fig. 2). 
EREQUENCY DISTRIBUTION OF MADDOX ROD AND SYNOPTOPHORE REAPINGS

[RE. FIXINE] BASED ON 100 PERSONS

NOVEMBER 1945

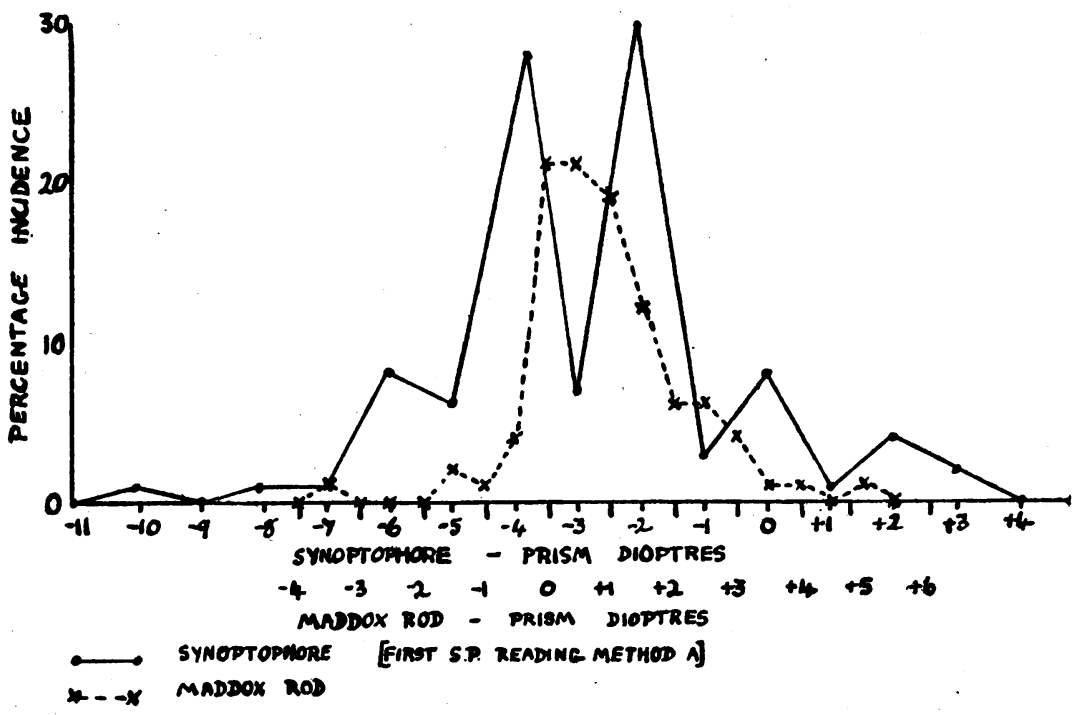

FIG. 2 .

(iii) The synoptophore readings are spread over a wider range than the Maddox rod readings for the same people. (See Fig. 2).

\section{IDiscussion}

With both the simultaneous perception and the fusion slides there was a statistically significant difference between the results obtained with method A as compared with method B. The difference was in the same direction for both simultaneous perception and fusion. In general, the reading with method B was more esophoric than with method A. The difference could be explained in part at least by the convergent initial position of the slides using method B. Further, fusion and simultaneous perception are not in practice, point features, but rather events which occur within a certain range. The response given by the individual would therefore be dependent on whether he started from the convergent or divergent position. In starting from the convergent position he would enter first the more esophoric portion of the range of fusion, and similarly from the divergent position when the more exophoric portion would be first entered. This shows that from the practical point of view it is essential :-

(a) To make the measurements on each occasion with the tube in the same initial position.

(b) To employ always the reading from the convergent position or the reading from the divergent position, but not sometimes from 
the one and sometimes from the other. For some work the mean of the readings from the two opposite initial positions could be used.

It is obvious from this group of symptom-free people that there is a wide range of normality. If the range "mean - standard deviation to mean + standard deviation" is taken as normal, then the following are suggested as the figures for the normals of the various 'measurements :-

Simultaneous perception and fusion.

Method $A-0.5$ to -5.5 prism dioptres

Method $B+1.0$ to -4.0 prism dioptres

Abduction $\quad \ldots \quad \therefore-4.5$ to -10 prism dioptres

Adduction $\quad \ldots \quad \ldots+4$ to +52 prism dioptres

\section{Recommendations}

It is recommended that subjective measurements on the synoptophore be taken by either method A or else by method B, as the results obtained by method A differ from those obtained by method B. Of the two methods, it is suggested that method A is preferable to method $B$.

\section{Summary}

Ninety-eight aircrew personnel and two W.A.A.F. were examined on the synoptophore and Maddox rod. In addition each person had his visual acuity and inter-pupillary distance measured.

On the synoptophore, simultaneous perception and fusion were both measured subjectively by two different methods (A and B). Four simultaneous perception readings and two fusion readings were taken by each method. It was found that there was no significant difference between successive simultaneous perception and fusion readings obtained by the same method (either A or B), but there was a significant difference between simultaneous perception and fusion readings obtained by method $\mathrm{A}$ as compared with method $\mathrm{B}$. The test-retest correlation for simultaneous perception was high $(+0.926)$, and the figures for fusion suggest that the test-retest correlation there is also high.

Two abduction and two adduction measurements were taken in succession on each person on the synoptophore. No significant difference was found in the two successive readings of either abduction or adduction.

By studying the means and standard deviations of the various synoptophore readings, a "normal" range was calculated for each type of reading. The range of "normal" adduction readings was found to be very large.

Maddox rod and synoptophore readings (right eye fixing in each case) were compared, and the correlation co-efficient was found to be +0.479 . The synoptophore readings were more exophoric and spread over a wider range than the Maddox rod readings. 


\begin{tabular}{|c|c|c|c|c|c|c|c|c|c|c|c|c|c|c|c|}
\hline \multirow{3}{*}{$\begin{array}{l}\text { Subject } \\
\text { No. }\end{array}$} & \multirow{3}{*}{\multicolumn{2}{|c|}{ R. V. A. ${ }_{L}$}} & \multirow{3}{*}{ M. R. } & \multirow{3}{*}{$\begin{array}{l}\text { P.D. } \\
\text { mm. }\end{array}$} & \multicolumn{11}{|c|}{ Synoptophore } \\
\hline & & & & & \multicolumn{4}{|c|}{$\begin{array}{l}\text { Simultaneous } \\
\text { Method }\end{array}$} & \multicolumn{2}{|l|}{$\begin{array}{l}\text { Perception } \\
\text { Method }\end{array}$} & \multicolumn{2}{|c|}{ Method Method } & & \multirow{2}{*}{ 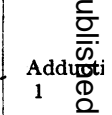 } \\
\hline & & & & & 1 & 2 & 3 & 4 & $1 \quad 2^{D} 3$ & 4 & $1^{\mathrm{A}} 2$ & ${ }_{1}{ }_{2}$ & $\begin{array}{c}\text { Abau } \\
11\end{array}$ & uction & \\
\hline 1 & & & +1 & 65 & -4 & -4 & -4 & $-4^{-1}$ & $-2-2-2-$ & -2 & $-2--2$ & $-2-2$ & -8 & -6 & -44 \\
\hline 2 & & $6 / 5$ & +1 & 69 & +2 & 0 & 0 & & $+1+2+2$ & +2 & & +6 & & & +50 \\
\hline & & $6 / 5$ & $-1 \frac{1}{2}$ & 6 & -4 & -4 & -3 & -3 & $-2-2$ & & $-4-4$ & $-2-2$ & & & \\
\hline 4 & & $6 / 6$ & $-\frac{1}{2}$ & 64 & -6 & -6 & -8 & -7 & $-5-4-5$ & -4 & $-4-5$ & $0+2$ & -6 & & \\
\hline 5 & & $6 / 6$ & 0 & 63 & 0 & -1 & -2 & -2 & $-2-1-2$ & -2 & $-5-5$ & $-4-5$ & -9 & -10 & \\
\hline 6 & 6 & $6 / 5$ & 0 & 70 & -1 & -3 & -2 & -3 & $+1+1+2$ & & $-2-4$ & $-2-3$ & -9 & -8 & \\
\hline 7 & 6 & $6 / 6$ & $+1 \frac{1}{2}$ & 60 & +2 & +2 & +2 & +2 & $+5+5+6$ & +5 & 0.0 & $+3+4$ & -4 & -3 & \\
\hline 8 & 16 & $6 / 6$ & 0 & 63 & -2 & -4 & -3 & -4 & $-4-3-2-$ & -4 & $-2-2$ & $-2-3$ & -7 & -5 & 16 \\
\hline 9 & 6 & $6 / 5$ & 0 & 67 & 0 & -6 & -4 & -6 & $-4-2-2$ & & $-4-4$ & -4 & -7 & -6 & \\
\hline 10 & 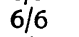 & $6 / 6$ & $+\frac{1}{2}$ & 64 & +2 & +2 & +2 & +2 & $+4+2+2$ & +2 & $0-1$ & $-1-1$ & -4 & -2 & +5 \\
\hline & & $6 / 6$ & +1 & 65 & +1 & +1 & 0 & +1 & $00+1$ & +1 & $+1+4$ & $0-1$ & -9 & -8 & \\
\hline 1 & & $6 / 5$ & 0 & 64 & +3 & +2 & +3 & +3 & $+3+3+3$ & +3 & +1 & $-1-1$ & -6 & -4 & \\
\hline 1 & $6 / 5$ & $6 / 5$ & +1 & 61 & -4 & -6 & -4 & -4 & $-2 \quad 0-1$ & -2 & $-4-5$ & $-3-2$ & -9 & -9 & \\
\hline 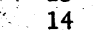 & 6 & $6 / 6$ & 0 & 65 & -2 & -3 & -3 & -2 & $0 \quad 0+1$ & & $-3-5$ & $-4-2$ & -12 & -10 & \\
\hline 1 & 8 & $6 / 5$ & 0 & 66 & -5 & -6 & -6 & -6 & $-5-4-5$ & -5 & $-6-5$ & $-5-5$ & -9 & -9 & \\
\hline 1 & $6 / 6$ & $6 / 6$ & +2 & 67 & -5 & -5 & -4 & -4 & $-3--4-3$ & -3 & $-4-4$ & $-3-2$ & -9 & -8 & \\
\hline$i$ & 6 & 6,6 & +3 & 65 & -1 & 0 & 0 & 0 & $0-2-1$ & & 0 & 0 & -8 & & \\
\hline 18 & 6 & $6 / 5$ & +1 & 63 & 0 & 0 & 0 & 0 & $00+2$ & +2 & $-2-3$ & 0 & -5 & -4 & \\
\hline 19 & $6 / 9$ & $6 / 6$ & $+\frac{1}{2}$ & 69 & -5 & -4 & -4 & -4 & $-4-4-4$ & & $-4-4$ & $-4-2$ & -10 & -8 & \\
\hline$x$ & $10 / 9$ & $6 / 6$ & +5 & 69 & -4 & -3 & -3 & -4 & $-2-2-2$ & -1 & $-2-2$ & $-1-2$ & -5 & -4 & \\
\hline 21 & $6 / 12$ & $6 / 9$ & +2 & 67 & -7 & -7 & -8 & -10 & $-4-4 \quad 0$ & & $-6-8$ & $-4-4$ & -12 & -12 & \\
\hline 22 & 16 & $6 / 6$ & $+\frac{1}{2}$ & 67 & $\rightarrow$ & -5 & -5 & -5 & $-4-4$ & -4 & & $-2-3$ & -8 & -7 & \\
\hline 23 & $6 / 5$ & $6 / 18$ & & 66 & -4 & -2 & -4 & -3 & $-3-2-3$ & -2 & $-3-4$ & $-2-2$ & -6 & -6 & \\
\hline & $6 / 5$ & $6 / 6$ & $+3 \frac{1}{2}$ & 64 & +2 & +2 & +2 & +3 & $+4+4+4$ & +4 & $+4+4$ & $+5+6$ & -4 & -4 & \\
\hline 25 & 619 & $6 / 9$ & +3 & 63 & -2 & -2 & -2 & -2 & +2 & & 19 & $0+2$ & -8 & -6 & \\
\hline 26 & $6 / 6$ & $6 / 6$ & 0 & 64 & -5 & -5 & -5 & -6 & $-5-4-4$ & -4 & $-4-4$ & $-2-2$ & -9 & -10 & \\
\hline 27 & $6 / 6$ & $6 / 6$ & 0 & 64 & -4 & -4 & -4 & -4 & $-3-2-2$ & -3 & $-5-6$ & $-4-2$ & -10 & -8 & \\
\hline 28 & $6 / 12$ & $6 / 12$ & $-\frac{1}{2}$ & 64 & -2 & -4 & -4 & -5 & $-4-2$ & & -4 & $-2-1$ & -10 & & \\
\hline 2 & $6 / 6$ & $6 / 6$ & 0 & 64 & -4 & -4 & -4 & -4 & $-4-4-3$ & -4 & -6 & $-6-5$ & -12 & -10 & \\
\hline 30 & $6 / 6$ & $6 / 6$ & +2 & 66 & -2 & -2 & -2 & -2 & -2 & & -2 & $-2-2$ & -7 & -5 & \\
\hline 31 & $6 / 6$ & $6 / 6$ & 0 & 67 & -2 & -2 & -3 & -3 & $-2-2-2$ & -2 & - & $-2-1$ & -10 & & \\
\hline 32 & $6 / 9$ & $6 / 6$ & +1 & 63 & -1 & -1 & -1 & -1 & $-1-1$ & -1 & $+1+1$ & 0 & -4 & -4 & \\
\hline 33 & $6 / 5$ & $6 / 5$ & 0 & 60 & -4 & -2 & -2 & -3 & $-3-2-2$ & -2 & $-3-$ & 0 & -11 & -12 & \\
\hline 34 & $6 / 5$ & $6 / 5$ & +1 & 66 & -4 & -5 & -5 & -5 & $-2-2-2$ & & -4 & $-4-2$ & -9 & -8 & \\
\hline 3. & $6 / 5$ & $6 /$ & 0 & 65 & -4 & -4 & -4 & -4 & $-3-3-2$ & -2 & $-6-6$ & $-5-4$ & -10 & -8 & \\
\hline 36 & $6 / 5$ & $6 / 5$ & $+\frac{1}{2}$ & 65 & -4 & -2 & -3 & -4 & $-4-2-2$ & & 2 & $0+2$ & -4 & -6 & \\
\hline & $6 / 9$ & $6 / 6$ & $+\frac{1}{2}$ & 61 & -2 & -4 & -4 & -2 & $+2+2$ & +1 & -7 & -1 & -9 & -8 & \\
\hline 3 & $6 / 5$ & $6 / 6$ & $+2 \frac{1}{2}$ & 64 & -4 & -4 & -2 & -4 & $-2-2-4$ & -2 & $-4-5$ & $-3-2$ & -6 & -6 & \\
\hline 39 & $6 / 6$ & $6 / 5$ & +1 & 63 & -2 & -2 & -2 & -2 & $-2-2-2$ & -2 & & $-1-1$ & -4 & -2 & \\
\hline $4 C$ & $6 / 5$ & $6 / 5$ & $+\frac{7}{2}$ & 65 & -2 & -2 & -4 & -4 & $0-2-2$ & -2 & -3 & $+1+1$ & -8 & -8 & \\
\hline 41 & $6 / 9$ & $6 / 9$ & 10 & 67 & -2 & -2 & -2 & -2 & +2 & & $-3-4$ & $-2-2$ & -5 & -5 & \\
\hline 42 & $6 / 5$ & $6 / 5$ & $+2 \frac{1}{2}$ & 70 & -2 & -1 & -1 & & & 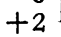 & $0+1$ & -1 & -6 & -6 & \\
\hline & $6 / 6$ & $6 / 6$ & & 70 & -5 & -4 & -5 & -4 & $-2-1-2$ & -1 & $-7-6$ & $-6-4$ & -8 & -9 & \\
\hline 44 & $6 / 6$ & $6 / 6$ & $+\frac{1}{2}$ & 62 & 0 & -2 & -3 & -2 & $0-1-1$ & & $-3-2$ & 0 & -7 & -4 & \\
\hline 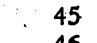 & $6 / 6$ & $6 / 6$ & $+\frac{5}{2}$ & 66 & -4 & -4 & -4 & -4 & $-2-2-1$ & & 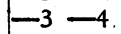 & -2 & -7 & -6 & \\
\hline 40 & $6 / 5$ & $6 / 5$ & t & 67 & -3 & -3 & -3 & -4 & $-2-2-2$ & -1 & -2 & $-2-1$ & -6 & -5 & \\
\hline 47 & $6 / 6$ & $6 / 9$ & $+1 \frac{1}{2}$ & 63 & -6 & -6 & -4 & -5 & $-2 \quad 0-2$ & -2 & $-6-$ & $-4-2$ & -8 & -8 & \\
\hline 48 & $\begin{array}{l}6 / 6 \\
6 / 9\end{array}$ & $6 / 6$ & $+1 \frac{\pi}{2}$ & 59 & -8 & -9 & -8 & -7 & $-4-3-3$ & -2 & $-6-$ & $-2+1$ & -10 & -8 & \\
\hline 40 & $6 / 9$ & $6 / 6$ & $+1 \frac{1}{2}$ & 62 & -4 & -2 & -4 & -3 & $-2-2-2$ & & $-2-$ & $-2-2$ & -6 & -6 & \\
\hline 50 & $6 / 6$ & $6 / 5$ & $+1 \frac{1}{2}$ & 62 & -2 & -2 & -4 & -4 & $-3-3-2$ & - & $-4-$ & $-2-2$ & -8 & -8 & \\
\hline 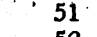 & $6 / 5$ & $6 / 5$ & $+\frac{1}{2}$ & 68 & -5 & -5 & -4 & -5 & $-4-4-3$ & - & $-5-$ & $-5-5$ & -8 & -8 & \\
\hline 5 & $6 / 6$ & 61 & +2 & 64 & -4 & -5 & -5 & -5 & $-4-$ & & - & -2 & -10 & -9 & \\
\hline & & $6 / 6$ & & 63 & -2 & & - & & & & & & -8 & -6 & +5 \\
\hline
\end{tabular}


INVESTIGATION OF "NORMAL" ON THE SyNOPTOPHORE

APPENDIX-continued

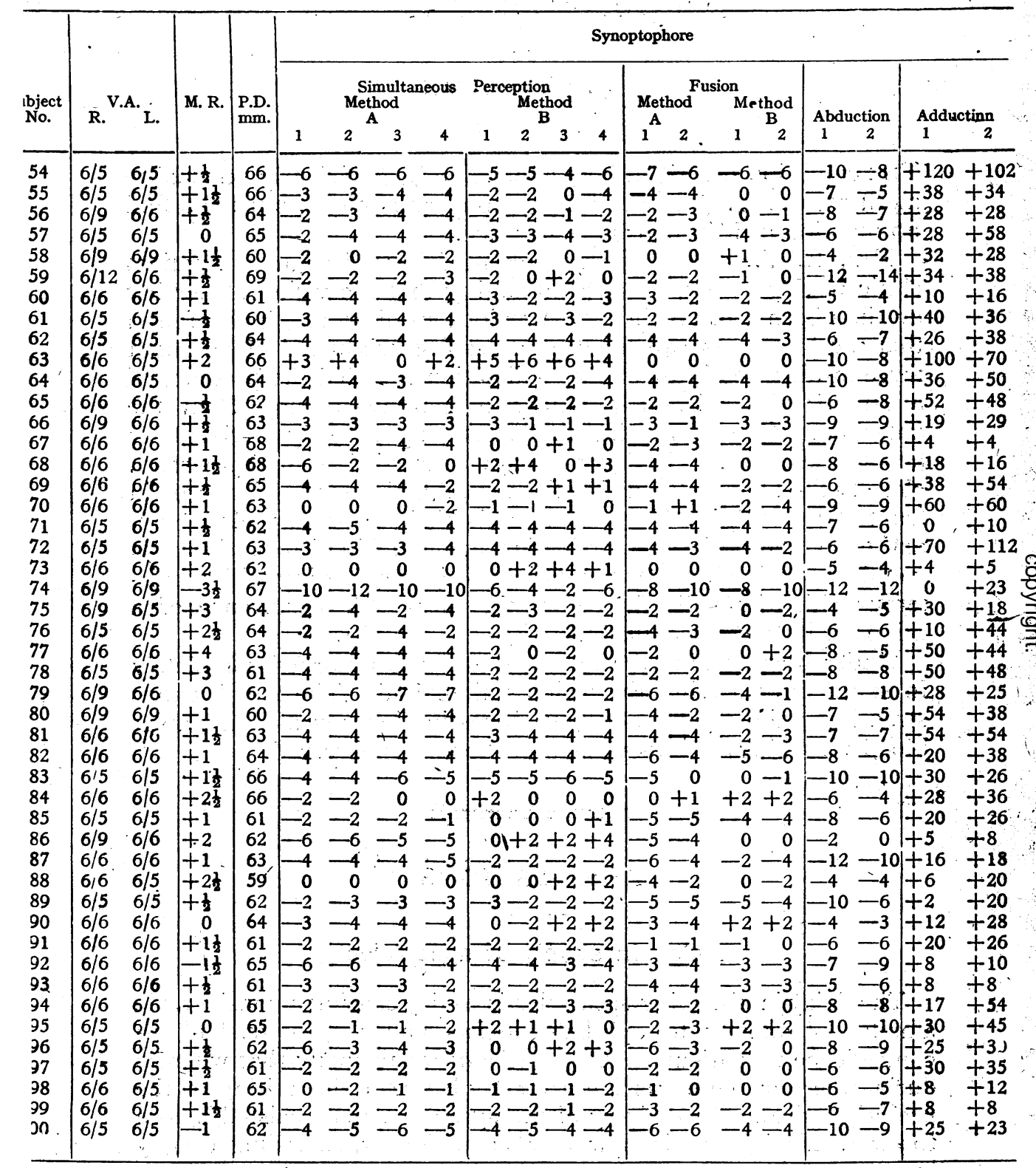

*W.A.A.F. personnel.

Maddox rod and synoptophore readings are in prism dioptres. 